REVISTA CATALANA DE DRET AMBIENTAL Vol. III Núm. 2 (2012): 1 - 18

- Crònica -

\title{
DERECHO Y POLÍTICAS AMBIENTALES EN CANTABRIA
}

\author{
Marcos Gómez Puente \\ Catedrático de Derecho Administrativo \\ Universidad de Cantabria
}


SUMARIO: 1. La polémica sobre los parques eólicos. 2. La nueva ordenación del suelo rural. 3. El contenido ambiental de la última ley de medidas administrativas. 4. El otorgamiento de concesiones en los montes de utilidad pública.

\section{La polémica sobre los parques eólicos}

El período que examinamos nos deja una nueva entrega, quizás la última, del conflicto derivado de la ordenación regional de parques eólicos. El procedimiento para la autorización de parques eólicos en la Comunidad se hallaba regulado por el Decreto 41/2000, de 14 de junio, otorgándose singularmente la autorización para cada parque previa presentación del correspondiente plan director eólico. Con arreglo a esta normativa, pues, se presentaron en menos de un año casi una veintena de planes para instalar parques que, en su conjunto, proporcionarían más de $500 \mathrm{MW}$ de potencia. Se hizo evidente, sin embargo, que las solicitudes para instalar parques eólicos superarían con mucho la capacidad de la región por albergarlos no solo por razones ambientales, sino también por motivos industriales, dada la imposibilidad de evacuar toda la energía potencialmente generable por la red eléctrica existente. Por ello, el Gobierno, después de autorizar planes para instalar 113 MW (en seis parques), decidió detener o suspender la autorización de nuevos parques (Acuerdo de 6 de abril de 2001, conocido como de "moratoria eólica") para estudiar cómo conciliar la elevada demanda de asentamientos eólicos tanto desde el punto de vista ambiental como mercantil (para limitar y organizar la concurrencia empresarial sin menoscabo de la necesaria competencia mercantil) e industrial (la potencia instalada debe guardar relación con la capacidad de las líneas eléctricas para evacuar la energía generada). Así, el Plan Energético de Cantabria 20062011 (PLENERCAN) consideró oportuno instalar inicialmente solo 300 MW y señaló las tres zonas que se consideraban más idóneas para hacerlo (Puerto de los Tornos, Sierra del Escudo y Campoo).

Más adelante el Gobierno encargó a la Universidad un estudio estratégico para el aprovechamiento de la energía eólica y se identificaron asentamientos en siete ámbitos territoriales para instalar hasta 1.500 MW, cota con la que supuestamente la región tendría garantizado su autoabastecimiento eléctrico y que podría ser evacuada por la red de transporte existente previsiblemente para el año 2020. Y teniendo presente ese estudio, el Decreto 19/2009, de 12 marzo, reordenó la instalación de parques eólicos en la Comunidad Autónoma de Cantabria, contemplando la convocatoria de un concurso público de asignación de potencia eólica. Esto es, las empresas interesadas podían 
concursar - y concursaron - para conseguir que les fuera reconocido el derecho exclusivo a instalar una determinada cota o capacidad de generación en cada uno de los ámbitos territoriales identificados como aptos para la generación. Una idea, por cierto, puesta también en práctica en Canarias (Orden de 27 de abril de 2007) y Galicia (Orden de 29 de marzo de 2010).

Así pues, el Decreto no determinaba la potencia o capacidad de generación que finalmente se instalaría en la Comunidad (cota o límite que tendría que determinarse en el plan energético regional) ni tampoco la ubicación exacta de los futuros parques. Lo que pretendía era ordenar la concurrencia de las empresas interesadas introduciendo un procedimiento, un concurso, para distribuir, entre las que resultaran elegidas y por ámbitos territoriales, la latente capacidad de generación eólica de la región. Más que realizar una asignación de potencia eólica concreta, pues, lo que se pretendía era hacer una reserva y distribución de la potencia eólica que en su momento pudiera asignarse y establecerse en cada ámbito territorial. De este modo, solo las empresas ganadoras de estas reservas, esto es, solo aquellas a las que se les hubiera "asignado" una potencia eólica, estarían en condiciones de solicitar autorizaciones para instalar parques eólicos en las zonas y hasta las cotas máximas de generación que se les hubieran asignado, sin que esta asignación, sin embargo, prejuzgara por sí sola el otorgamiento de las autorizaciones para la construcción y explotación de los parques eólicos que pudieran instalarse en la zona territorial asignada ni la capacidad de generación eólica finalmente autorizada e instalada (subordinada a las determinaciones del plan energético regional), ni concediera al titular ningún tipo de derecho sobre el otorgamiento de dichas autorizaciones o por la eventual denegación de estas.

En aplicación del Decreto, pues, en junio de 2009 se convocó un concurso público para la asignación de un máximo de potencia eólica de $1.400 \mathrm{MW}$ distribuidos en siete zonas territoriales y surgió una viva polémica alimentada, sobre todo, por la sustancial diferencia entre la potencia que se ha previsto asignar o repartir $(1.400 \mathrm{MW})$ y la que el PLENERCAN 2006-2011 preveía instalar (300 MW). Estos términos de potencia no eran comparables, pues la cota del PLENERCAN representaba una limitación concreta y real de la capacidad de generación instalable, mientras que la cota del concurso expresaba solo una reserva, de alcance potencial e hipotético, de la capacidad de generación instalable. 
Parece, sin embargo, que no se explicó bien esta diferencia o que se identificaron o confundieron los términos, y el activismo de algunas asociaciones ecologistas llevó al imaginario popular la imagen de una región repleta de aerogeneradores (con una elocuente campaña gráfica que ubicaba virtualmente los molinos en la bahía de Santander), a pesar de que el propio Gobierno — es verdad que tardíamente - ya había tratado de controlar, considerando el impacto visual, los excesos cometidos en alguna región limítrofe. Cundió la idea de que se instalarían los parques sin haber llevado a cabo antes una evaluación ambiental del desarrollo eólico en su conjunto (aunque se hiciera la de cada parque); de que el procedimiento de asignación antes descrito constituía un fraude de ley para eludir la normativa que exige la evaluación estratégica de planes y programas; y de que se trataba, en realidad, de una modificación encubierta del PLENERCAN. Y enseguida llegó la polarización política y social de unos y otros en apoyo (asociaciones empresariales, prensa regional, PSOE y, más tímidamente, PRC) u oposición (PP, asociaciones ecologistas) al desarrollo de los parques. Una polarización quizás exagerada, o un poco interesada, que no parece del todo justificada a la vista del contenido del Decreto, pero en la que llegó a terciar incluso el Defensor del Pueblo, que solicitó aclaraciones sobre el proceso de desarrollo de la energía eólica en la región.

Y así se avivó aún más la polémica, siendo este uno de los asuntos ambientales (el otro es el de los derribos de urbanizaciones ilegales) que mayor atención e interés social han acaparado en los últimos años, poniéndose en evidencia que en ocasiones no son solo el desarrollo o los objetivos económicos los que entran en conflicto con los objetivos específicos de una política ambiental, sino que también pueden ser los propios valores, intereses u objetivos ambientales —entre los que está la implantación de energías renovables - los que se contraponen o confrontan y han de conciliarse al definirla o ejecutarla.

En el caso que nos ocupa se aprecia con facilidad; sin duda, la fuente de energía más ecológica es la que no llega a utilizarse, la que no se consume ni desperdicia. Pero, dicho esto, también parece existir un cierto consenso acerca de la bondad y superior interés ecológico y ambiental de las denominadas energías renovables o verdes, expresión reservada para las que se obtienen de fuentes naturales virtualmente inagotables, como pueden serlo la energía solar o la energía eólica, y limpias, por lo que respecta a las emisiones de gases de efecto invernadero u otros contaminantes, en comparación con las generadas por los combustibles fósiles o las reacciones nucleares. 
Sin embargo, la propia ubicación y despliegue de los huertos solares o eólicos, por su impacto sobre el medio, puede entrar en conflicto con otros valores ecológicos, paisajísticos y culturales ambientalmente no menos relevantes. Y en esta contradicción tiene su origen la polémica suscitada por la reglamentación que nos ocupa.

El Gobierno regional salió al paso de estas críticas recordando (i) que el concurso y la asignación de potencia eólica únicamente tenían por objeto ordenar (espacialmente) la concurrencia mercantil de las empresas y la oferta, sin que ello significara que toda la potencia así asignada (reservada más bien, como se ha dicho) pudiera ser, al final, efectivamente instalada; (ii) que por su propio objeto y finalidad de regulación mercantil, las bases del concurso no prefiguraban el número, ni las características ni la ubicación final de los parques y carecían, por ello mismo, de la naturaleza propia de un plan, por lo que no resultaba procedente su evaluación ambiental estratégica; (iii) que la asignación (o reserva) de potencia eólica no prejuzgaba la observancia de la normativa y planificación vigente en el momento en que deba autorizarse cada parque eólico (como se advertía en las bases de la convocatoria y se infería de los artículos 8 y 9 del Decreto 19/2009 — aunque este, ciertamente, podía haber hecho una declaración más rotunda en tal sentido-); (iv) que la reserva o asignación de potencia eólica era condición necesaria, pero no suficiente, para la autorización de la instalación de parques eólicos, como se desprendía del artículo 2 del Decreto 19/2009, hallándose dicha autorización supeditada, además, al cumplimiento de la normativa vigente en cada caso, incluida la evaluación del impacto ambiental del proyecto de cada parque (por ello mismo, la asignación no confería per se derecho a implantar parques eólicos); y (v) que el PLENERCAN seguía vigente y que, por lo tanto, en el escenario temporal de este - que ha sido prorrogado por Decreto 173/2011, de 22 de diciembre (hasta que se apruebe el nuevo Plan de Sostenibilidad Energética para Cantabria, cuya preceptiva evaluación ambiental estratégica está en curso) - la potencia instalada no superaría los $300 \mathrm{MW}$, sin perjuicio de que este techo pueda ser elevado por futuros planes energéticos (que deberían, claro está, someterse a la correspondiente evaluación ambiental estratégica).

En cualquier caso, los esfuerzos del Gobierno para justificar su modelo no impidieron que la convocatoria del concurso fuera impugnada en vía contencioso-administrativa por la asociación ecologista ARCA, que también solicitó la suspensión cautelar del concurso. La suspensión fue denegada mediante Auto de 13 de octubre de 2010 (que impugnado en reposición fue confirmado por otro de 24 de marzo de 2011) y el 
concurso siguió su curso, resolviéndose este a finales de 2011, mientras seguía pendiente el recurso contencioso-administrativo contra la convocatoria. Y sobre este recurso, precisamente, acaba de recaer ahora sentencia estimatoria.

En efecto, la STSJ de Cantabria de 17 de octubre de 2012 declara contraria a derecho y nula la convocatoria del concurso porque considera, en síntesis, que constituye una planificación encubierta, esto es, realizada al margen del procedimiento legalmente establecido, aunque salva, paradójicamente, la legalidad del Decreto de la que trae causa y fundamento la propia convocatoria.

Así, la Sala cántabra considera que "lo que realmente se está haciendo, en la base de desarrollo del concurso impugnado, es planificar tanto el sector eléctrico como la ordenación del territorio, utilizando para ello, nada más y nada menos, que una base de desarrollo de un decreto por el que se convoca un concurso". Invocando la exposición de motivos de la Ley 54/1997, de 27 noviembre, del Sector Eléctrico, la Sala explica que tras la liberalización de este sector la planificación estatal ha quedado restringida a las instalaciones de transporte, por su imbricación en la planificación urbanística y en la ordenación del territorio, pero que sigue siendo viable y útil, para facilitar la inversión de los agentes económicos, una planificación pública indicativa, como la del PER (estatal) o el PLENERCAN (autonómica), siempre que tenga lugar a través de los instrumentos y procedimientos adecuados. $\mathrm{Y}$ esto último, precisamente, es lo que la Sala reprocha al Gobierno regional: haber tratado de modificar la planificación energética vigente (el PLENERCAN) sin atenerse a lo dispuesto en la legislación urbanística y ambiental.

Así, advierte la Sala, "es claro que lo que se intentaba era una zonificación del territorio de la Comunidad, distinta de la prevista inicialmente, puesto que de tres zonas se pasaba a siete", constituyendo dicha zonificación un objeto propio de la ordenación del territorio que, por lo tanto, debería haberse efectuado a través de los instrumentos descritos (no especifica cuáles) en el título I de la Ley de Cantabria 2/2001, de 25 de junio, de Ordenación Territorial y Régimen Urbanístico del Suelo de Cantabria.

Luego añade que el Gobierno "no ha observado lo previsto en las leyes 9/2006 y 17/2006 (Cantabria), desarrollo, entre otras, de la Directiva 97/11/CE” (o sea, en la legislación sobre evaluación ambiental), considerando insuficiente "que se evalúe el riesgo de cada instalación de parque eólico, en la fase posterior a la aprobación de este 
concurso", pues "es necesario que se evalúe el riesgo que para el medio ambiente pueda suponer la totalidad del desarrollo de la energía eólica en la Comunidad Autónoma y el resto del país". Por la misma razón — explica el fallo- que el PER y el PLENERCAN fueron sometidos a evaluación ambiental estratégica, debería haber sido objeto de esta la convocatoria impugnada, toda vez que esta (i) había sido aprobada por una Administración, (ii) venía exigida por una disposición reglamentaria (el citado Decreto 19/2009) y (iii) tenía efectos significativos sobre el medio ambiente por constituir el marco para la futura autorización de proyectos legalmente sometidos a evaluación de impacto ambiental en materia energética, concitándose así las condiciones en que dicha evaluación resulta obligada de acuerdo con el artículo 3 de la Ley 9/2006, de 28 de abril, sobre evaluación de los efectos de determinados planes y programas en el medio ambiente.

La ratio decidendi del fallo, por consiguiente, parece hallarse en la consideración de que la convocatoria — por sus bases reguladoras - venía a modificar las determinaciones (zonales y energéticas) del PLENERCAN y que, por ello, tenía materialmente la misma naturaleza que este y debía haber seguido el curso procedimental propio de este planeamiento, incluida la evaluación ambiental.

La equiparación que hace el Tribunal resulta, ciertamente, discutible, pues, como se ha dicho antes, atendiendo a la finalidad y efectos del concurso no parece que los beneficiarios tuvieran que ser necesariamente autorizados a instalar toda la potencia reconocida, ni que pudieran sustraerse a las determinaciones del PLENERCAN ni que sus proyectos pudieran sustraerse a las determinaciones del planeamiento urbanístico o de la legislación ambiental, razón por la que tampoco parece posible concluir que la convocatoria viniera a dispensar o modificar el planeamiento energético o territorial. Pero parece también que el Gobierno no ha sabido hacerse entender y que la misma convocatoria, incluso, ha podido propiciar la confusión sobre su finalidad y efectos, al calificar como concurso para la "asignación de potencia eólica" lo que en realidad no era más que un concurso para la "reserva de potencia eólica" eventualmente instalable. Óptica esta última, la de la reserva, desde la que, por cierto, sí podían hacerse algunas objeciones al procedimiento selectivo, pero de índole mercantil, de defensa de la competencia, pues la aludida reserva por la que concursaban las empresas podía quedarse disminuida, vaciada parcialmente de contenido, si finalmente, por razones industriales, territoriales o ambientales, no podía localmente instalarse la capacidad de 
generación pretendida, quedando afectada la igualdad de oportunidades que el concurso debía salvaguardar. Pero desde esta perspectiva no se han escuchado objeciones.

En cualquier caso, el hilo argumental de la Sentencia se debilita en lo que atañe a la legalidad del Decreto 19/2009, pues si la convocatoria declarada ilegal y anulada trae causa de esta disposición reglamentaria y se ha limitado a cumplir o aplicar lo dispuesto en su artículo 5.3 (que es el que regula el concurso y exige, en su apartado a), que las bases de la convocatoria determinen la "potencia eólica máxima a instalar y las zonas de implantación territorial de dicha potencia"), parece que también debería haberse declarado ilegal y nulo este precepto, por autorizar que la zonificación o limitación de potencia pudiera hacerse por los trámites de aprobación de las bases del concurso. Sin embargo, la Sala no declara nulo dicho precepto y entiende (apartándose, por cierto, del criterio del Defensor del Pueblo) que no es dicha disposición la que tiene naturaleza planificadora, sino solo la base que desarrolla el concurso, pues es "la que adopta decisiones de desarrollo del sector energético y de planificación del territorio”, y que, precisamente por ello, la propia disposición exigía a las entidades interesadas que dicha base fuera objeto de audiencia con carácter previo a su aprobación. No obstante, es posible que la Sala haya considerado legal la disposición interpretando que la autorización que contenía para zonificar o limitar potencia en las bases del concurso quedaba circunscrita a las zonas y cota máxima ya establecidas por el PLENERCAN, aunque la Sentencia nada aclara a este respecto.

En fin, el asunto tiene complejidad y la argumentación del fallo es controvertible, por lo que podrían encontrarse motivos para impugnar la Sentencia en instancia superior. Sin embargo, el Gobierno regional, dirigido ahora por un partido (PP) que en su día se opuso a la convocatoria, ha hecho ya pública su intención de no recurrir la Sentencia, como parece que presumiblemente tampoco van a hacerlo las empresas en su día beneficiadas - y codemandadas_-, aunque la Asociación Eólica de Cantabria (AEC), en la que se integran, recalcando que mantiene su compromiso de colaboración institucional, ha precisado que corresponde a cada uno de los grupos adjudicatarios del concurso eólico decidir individualmente si interponen o no un recurso ante el Tribunal Supremo y si reclaman indemnizaciones por la anulación. 


\section{La nueva ordenación del suelo rural}

Otra novedad que arroja el año 2012 es la modificación parcial de la Ley de Cantabria 2/2001, de 25 de junio de 2001, de Ordenación Territorial y Régimen Urbanístico del Suelo de Cantabria, efectuada por la Ley 3/2012, de 21 de junio, con el propósito de ampliar la utilidad edificatoria del suelo rústico.

Lo que pretende el legislador es facilitar la construcción de viviendas y el establecimiento de actividades económicas en el suelo rústico, si bien que de forma controlada y condicionada, con el fin de dinamizar el medio rural. Guiada por el principio de sostenibilidad, pues, la reforma viene a establecer un nuevo punto de equilibrio entre la necesaria protección del suelo rústico y el igualmente necesario desarrollo del medio rural, tratando de propiciar su reactivación económica en el escenario general de crisis. Aunque la conveniencia del reactivo que utiliza - la actividad constructiva - resulta cuestionable o controvertida cuando se encuentra ya ampliamente aceptada la necesidad de abandonar el modelo productivo del ladrillo y encontrarle alternativas.

La diversificación del catálogo de usos del suelo rústico también facilita, en cualquier caso, la búsqueda de esas alternativas y concuerda con la filosofía latente en la más reciente legislación estatal básica (artículo 9.2 de la Ley del Suelo, Real Decreto Legislativo 2/2008, de 20 de junio), que concibe el suelo rural como un suelo sustraído del proceso urbanizador, pero no descarta su edificabilidad, si bien que limitada o condicionada y caracterizada para usos determinados acordes con su naturaleza.

Así, en primer lugar, la condición de suelo rústico de especial protección se reserva para los terrenos cuya transformación sea incompatible en razón de sus valores paisajísticos, históricos, arqueológicos, científicos, ambientales, culturales, agrícolas, de riesgos naturales acreditados o por su sujeción a limitaciones o servidumbres impuestas para la protección del dominio público y como tales se hayan clasificado por los planes generales de ordenación urbana (art. 108). Los restantes terrenos excluidos del proceso urbanizador por el planeamiento general tendrán la consideración de suelo rústico de protección ordinaria (art. 109).

En el suelo rústico quedan prohibidas las divisiones, segregaciones o fraccionamientos de terrenos de cualquier tipo salvo para facilitar la concentración de propiedades o el destino de las fincas resultantes a cualquier tipo de usos no agrarios consentidos por la 
ley, con expresa exclusión de las construcciones residenciales colectivas, urbanizaciones y otras actuaciones propias del entorno urbano (art. 111).

En el suelo rústico de especial protección (art. 112) se prohíben las construcciones, instalaciones, actividades y usos que impliquen transformación de su naturaleza y destino, y si existen instrumentos sectoriales de protección (un PORN, por ejemplo), el régimen de usos será el previsto en ellos, salvo que el planeamiento municipal establezca uno más restrictivo. Salvo que esté específicamente prohibido, se podrán autorizar, con carácter excepcional y en las condiciones previstas en los instrumentos de protección, las siguientes construcciones, instalaciones, actividades y usos: a) las necesarias para las explotaciones agrícolas, ganaderas, forestales y otras análogas que guarden relación con la naturaleza, extensión y utilización de la finca, incluidas las viviendas de las personas que hayan de vivir y vivan real y permanentemente vinculadas a la correspondiente explotación; b) las que sean complementarias de las explotaciones anteriormente mencionadas (incluidas las que tengan por objeto la transformación y venta directa de los productos agrarios, así como las actividades turísticas, cinegéticas, artesanales, culturales, educativas y cualesquiera otras complementarias de la actividad realizada en dichas explotaciones); c) las que estén vinculadas a la ejecución, el entretenimiento y el servicio de obras públicas e infraestructuras; d) las que sean consideradas de interés público o social por la Administración sectorial correspondiente; e) aquellas en las que se lleven a cabo usos que fuera imprescindible ubicar en suelo rústico, bien por ser ese su normal ámbito de desarrollo, bien por ser inadecuado para ello el suelo urbano; f) las actividades extractivas y las construcciones vinculadas a ellas, siempre que se trate de un suelo rústico especialmente protegido para esa finalidad; g) la ampliación de usos, instalaciones y construcciones cuya ubicación en suelo rústico sea imprescindible por ser la única clase de suelo adyacente en la que puede llevarse a cabo esta ampliación, adoptándose las medidas de integración paisajística adecuadas; y h) las obras de reconstrucción, restauración, renovación y reforma de edificaciones preexistentes, para ser destinadas a cualquier uso compatible con la legislación sectorial, así como con el planeamiento territorial y urbanístico, incluido el uso residencial, cultural, artesanal, de ocio o turismo rural, siempre que no impliquen aumento de volumen.

En relación con esta última clase de actuación, es preciso advertir que la Ley exige ahora que los planes generales de ordenación urbana incorporen un catálogo de 
edificaciones en suelo rústico que incluya las edificaciones existentes con características arquitectónicas, tipológicas y constructivas propias de una edificación rural del entorno (art. 45.j). Pues bien, si las edificaciones preexistentes estuvieran incluidas en dicho catálogo, se permite su reconstrucción y la ampliación de la superficie construida hasta un veinte por ciento, para dotar a la edificación de unas condiciones de habitabilidad adecuadas y para servir al uso al que se destine, siempre que se conserven, restauren o mejoren los caracteres arquitectónicos que determinaron su inclusión en el catálogo. Y si no estuvieran catalogadas por haber perdido los caracteres arquitectónicos rurales propios de su entorno, se puede solicitar una autorización de obras de restauración, renovación y reforma (también con la referida ampliación de la superficie construida) para la recuperación de dichos caracteres y su posterior catalogación.

En el suelo rústico de protección ordinaria (art. 113) podrán autorizarse, salvo que los instrumentos de planificación sectorial o territorial dispongan un régimen más restrictivo, las siguientes construcciones, instalaciones, actividades y usos: a) todas las autorizables en el suelo rústico de especial protección; b) las necesarias para la realización de actividades relativas a la elaboración y comercialización de productos tradicionales o derivados de la actividad agropecuaria, y los servicios complementarios de dichas actividades; c) las actividades extractivas y las construcciones vinculadas a ellas; d) los usos deportivos y de ocio sin instalaciones asociadas o con instalaciones desmontables necesarias para la realización de la actividad, así como las instalaciones deportivas y de ocio descubiertas que, o bien sean accesorias de construcciones e instalaciones preexistentes, o bien ubiquen sus construcciones asociadas apoyándose en edificios preexistentes, sin perjuicio de la posible adecuación a estos nuevos usos; y e) la construcción de viviendas unifamiliares aisladas, así como de instalaciones vinculadas a actividades artesanales, culturales, de ocio y turismo rural, en los términos previstos en los planes especiales de suelo rústico.

Por lo que hace a esta última clase de actuación, parece oportuno añadir que la Ley autoriza a los municipios (tengan o no planeamiento general o normas subsidiarias) a aprobar un plan especial de suelo rústico. Este plan puede calificar como suelo rústico de protección ordinaria terrenos próximos a los núcleos urbanos (las denominadas corolas) y a los núcleos tradicionales (o los propios núcleos, si no fueran urbanos), analizando su morfología y las características y los valores naturales y culturales de su entorno, a los efectos de delimitar el ámbito de proximidad a los núcleos, establecer las 
condiciones de uso y de integración en el entorno y en relación con los núcleos, así como determinar las directrices generales que las nuevas edificaciones o el aumento de volumen de las existentes deban seguir en cuanto a tamaño de parcela, distancia a colindantes, ocupación de parcela y altura de cierres, así como otras características morfológicas y tipológicas relevantes (nueva disposición adicional $5^{\mathrm{a}}$ ). Este tipo de determinaciones pueden también incorporarse directamente a los planes generales, sin necesidad de tramitar dicho plan especial.

La reforma ha introducido también unos estándares constructivos para la construcción en el suelo rústico, aplicables sin perjuicio de las condiciones más restrictivas que establezca el planeamiento o la legislación sectorial (y sin perjuicio de la observancia de las ordenanzas municipales que determinen las condiciones estéticas y de diseño permitidas). Así, a) las actuaciones han de sujetarse a las normas de aplicación directa de la propia Ley (sobre protección ambiental, cultural, paisajística, pantallas vegetales, etc., artículo 32 ss.); b) quedan particularmente prohibidas las construcciones residenciales colectivas, urbanizaciones $\mathrm{u}$ otras propias del entorno urbano; c) las edificaciones deben adecuarse a la pendiente natural del terreno, de modo que esta se altere el menor grado posible; d) corren por cuenta del promotor las infraestructuras necesarias para obtener los servicios residenciales típicos (abastecimiento, evacuación y tratamiento de aguas; suministro de energía eléctrica; recogida, tratamiento, eliminación y depuración de toda clase de residuos; etc.), recordando expresamente la Ley que "los propietarios de terrenos en suelo rústico no podrán exigir de las Administraciones Públicas obras de urbanización y servicios urbanísticos" (art. 111.2); e) parcela mínima de dos mil metros cuadrados (o incluso inferior, en el caso previsto en la disposición transitoria 9.9); f) los cerramientos se situarán a una distancia mínima del límite exterior de la calzada, vial o camino de tres metros y los propietarios deberán ceder gratuitamente los terrenos necesarios para la ampliación del viario preexistente; g) se respetarán y, en su caso, se repondrán los cierres de piedra perimetrales de la parcela objeto de edificación, y se respetarán los setos vivos y arbolado relevantes; h) la altura máxima de las viviendas que puedan autorizarse no será superior a nueve metros; i) las explotaciones agropecuarias permitidas por el planeamiento, así como sus ampliaciones, tendrán la condición de uso compatible con las construcciones residenciales y de ocio y turismo rural que se edifiquen; y j) las nuevas edificaciones deberán apoyarse en la red 
de caminos existente, salvo justificación expresa, introduciendo únicamente los viarios o caminos imprescindibles.

Ha de destacarse, por último, que el legislador, preocupado por la radical caída de la actividad económica, ha querido adelantar la efectividad real de la nueva ordenación mediante la disposición transitoria 9. ${ }^{\mathrm{a}}$, permitiendo que se autorice la construcción de viviendas aisladas de carácter unifamiliar, así como construcciones e instalaciones vinculadas a actividades artesanales, culturales, de ocio y turismo rural, antes incluso de que se aprueben los planes especiales de suelo rústico o de que se incorporen al planeamiento general las determinaciones propias de estos. Los ayuntamientos pueden, no obstante, excluir este régimen transitorio en todo o parte de su término municipal o establecer parámetros más restrictivos y limitativos que los previstos para este.

Así, se podrán autorizar dichas construcciones (i) en los municipios sin plan general o con normas subsidiarias si la edificación pretendida se sitúa (en la mayor parte de su superficie) a un máximo de cien metros del suelo urbano, salvo que los terrenos estén sometidos a un régimen especial de protección por planes o normas de ordenación territorial o por la legislación sectorial pertinente, o tengan valores intrínsecos que les hagan merecedores de una especial protección; y (ii) en los municipios con plan general o con normas subsidiarias si la edificación pretendida se sitúa en suelo rústico ordinario y a un máximo de doscientos metros del suelo urbano.

Es preciso, además, que: a) la edificación sea coherente con la arquitectura propia del núcleo y armónica con el entorno (alturas, volumen y materiales exteriores), tenga mínimo impacto visual sobre el paisaje y no altere significativamente el relieve natural de los terrenos; b) el número de viviendas autorizadas no supere el número de viviendas preexistentes en el núcleo urbano; c) se observen los estándares constructivos para el suelo rústico previstos en la propia Ley; d) se observen las condiciones estéticas y de diseño eventualmente contenidas en las ordenanzas municipales; e) la edificación tenga una parcela mínima de $2.000 \mathrm{~m}^{2}$ (o incluso de solo $1.500 \mathrm{~m}^{2}$ si la mayor parte de la edificación pretendida se encuentra a una distancia de hasta cincuenta metros del borde del suelo urbano delimitado o del núcleo tradicional); f) la edificación ocupe como máximo el $10 \%$ de la superficie bruta de la parcela si esta es superior a $2.000 \mathrm{~m}^{2}$; o tenga un máximo de $200 \mathrm{~m}^{2}$ por planta si la superficie bruta de la parcela está entre 1.500 y $2.000 \mathrm{~m}^{2}$; u ocupe como máximo el 15\% de la superficie bruta de la parcela si se utiliza combinadamente como vivienda y lugar de una actividad artesanal o de ocio y 
turismo rural; g) la distancia mínima de la edificación al lindero sea de cinco metros; y h) el frente mínimo de parcela a vía pública o camino público o privado sea de tres metros.

Tales son las condiciones, pues, en las que puede darse ahora una nueva actividad constructiva en el medio rural.

\section{El contenido ambiental de la última ley de medidas administrativas}

Si en la última crónica dejamos anotada la significación ambiental de la Ley de Cantabria 5/2011, de 29 de diciembre, de Medidas Fiscales y Administrativas, aprobada en paralelo a la Ley de Presupuestos para 2012, ahora debemos hacer lo mismo con la Ley de Cantabria 2/2012, de 30 de mayo, de Medidas Administrativas, Económicas y Financieras, cuyas determinaciones van también dirigidas a cumplir los objetivos de reducción del déficit regional en el marco del compromiso del Gobierno de la nación ante la Unión Europea.

Entre las medidas adoptadas en esta ocasión aquí interesa mencionar, por su relación con la materia ambiental, la supresión del Consejo Económico y Social de Cantabria (art. 15), órgano consultivo creado hace dos décadas (Ley de Cantabria 6/1992, de 26 de junio) que tenía atribuida, entre sus funciones, la de dictaminar proyectos normativos y elaborar estudios e informes sobre diversas materias, entre las que se incluía el medio ambiente. La colección de sus dictámenes y memorias socioeconómicas sigue estando accesible a través del sitio electrónico del órgano (www.cescan.es), el cual, acertadamente, se ha mantenido vivo como repositorio de dicha documentación, resultando esta útil para contrastar la conflictividad latente en los proyectos normativos y la evolución del estado ambiental de la región en la última década.

Otra novedad, sin alcance institucional, es la modificación de la Ley de Cantabria 2/2002, de 29 de abril, de Saneamiento y Depuración de las Aguas Residuales, para actualizar el precio de los componentes del Canon de Saneamiento (art. 31.4), que mantiene la tendencia al alza de los últimos años. Tras la última subida (un 3\%) en enero de 2012, el incremento acumulado desde la entrada en vigor del Canon en 2003 era de un 40\%. Pero el escalón que marca la última modificación es muy significativo, pues se trata de un incremento próximo al $30 \%$ : 


\begin{tabular}{|c|c|c|c|}
\hline & Desde 02/06/2012 & Hasta 01/06/2012 & $\Delta(\%)$ \\
\hline \multicolumn{4}{|c|}{ Componente fijo } \\
\hline Abonado / Sujeto pasivo & $19,92 € /$ año & $15,32 € /$ año & 30,02 \\
\hline \multicolumn{4}{|c|}{ Componente variable } \\
\hline Régimen general para usos domésticos & $0,3749 € / \mathrm{m}^{3}$ & $0,288400 € / \mathrm{m}^{3}$ & 29,99 \\
\hline Régimen general para usos industriales & $0,4871 € / \mathrm{m}^{3}$ & $0,374714 € / \mathrm{m}^{3}$ & 29,99 \\
\hline \multicolumn{4}{|c|}{\begin{tabular}{|l} 
Régimen de medición directa de la carga contaminante \\
\end{tabular}} \\
\hline Materias en suspensión (MES) & $0,3342 € / \mathrm{kg}$ & 0,264813 & 26,20 \\
\hline Demanda química de oxígeno (DQO) & $0,3871 € / \mathrm{kg}$ & $0,306734 € / \mathrm{kg}$ & 26,20 \\
\hline Fósforo total $(\mathrm{P})$ & $0,8444 € / \mathrm{kg}$ & $0,668985 € / \mathrm{kg}$ & 26,22 \\
\hline Materias inhibitorias (MI) & $6,6336 € /$ KEtox & $5,255884 € /$ KEtox & 26,21 \\
\hline Sales solubles (SOL) & $5,2962 € / \mathrm{Sim} / \mathrm{cm} / \mathrm{m}^{3}$ & $4,19622 € / \mathrm{Sim} / \mathrm{cm} / \mathrm{m}^{3}$ & 26,21 \\
\hline Nitrógeno total $(\mathrm{N})$ & $0,4224 € / \mathrm{kg}$ & $0,334647 € / \mathrm{kg}$ & 26,22 \\
\hline Incremento de temperatura (IT) & $0,000070 € /{ }^{\circ} \mathrm{C}$ & $0,000056 € /{ }^{\circ} \mathrm{C}$ & 25,00 \\
\hline
\end{tabular}

Igualmente intensa es la subida de la tasa por gestión final de residuos urbanos prevista en la Ley de Cantabria 9/1992, de 18 de diciembre, de Tasas y Precios Públicos de la Diputación Regional de Cantabria, cuya redacción se modifica para aclarar (i) que constituye su hecho imponible la prestación de los servicios de almacenamiento en los centros de transferencia y transporte hasta las instalaciones de valorización $\mathrm{o}$ eliminación, así como la gestión final de los residuos urbanos mediante valorización o eliminación; (ii) que son sujetos pasivos de la tasa los municipios, mancomunidades o consorcios en cuyo favor se presten o para los que se realicen dichos servicios; y (iii) que la tasa se devenga en el momento de entrega de los residuos urbanos en las plantas de transferencia o en las instalaciones de gestión final si son depositados directamente en estas. La tasa ha experimentado una subida del 33,92\%, situándose en $62,73 € / \mathrm{Tm}$.

Por otro lado, se ha procedido a reordenar la tasa por clausura de vertedero o depósito incontrolado de residuos sólidos urbanos, prevista también en la Ley de Cantabria 9/1992, de 18 de diciembre, introduciendo un tarifario nuevo para el cálculo de la tasa, también con el propósito de incrementar la recaudación y acercarla al coste real del servicio. Constituye hecho imponible de esta tasa la prestación, en sustitución de la entidad local obligada primeramente a ejercitar sus potestades de disciplina ambiental y ante la inactividad de esta, del servicio de clausura de un vertedero o depósito incontrolado de residuos sólidos urbanos. Son sujetos pasivos de la tasa, por lo tanto, las entidades locales para las que se presten estos servicios, devengándose aquella cuando se procede a la clausura del vertedero o depósito incontrolado.

Ahora la tarifa se diversifica (antes existía una única tarifa en función del volumen [peso] de residuo) del siguiente modo: 
- Tasa de clausura de vertederos o depósitos incontrolados con una cantidad menor a las 30 toneladas de residuos y situados a una distancia menor o igual a $50 \mathrm{~km}$ del gestor autorizado del residuo (Tipo A, Distancia 1): 152,20 €/Tm.

- Tasa de clausura de vertederos o depósitos incontrolados con una cantidad menor a las 30 toneladas de residuos y situados a una distancia mayor de $50 \mathrm{~km}$ del gestor autorizado del residuo (Tipo A, Distancia 2): 158,85€/Tm.

- Tasa de clausura de vertederos o depósitos incontrolados con una cantidad mayor o igual a 30 toneladas y menor a 150 toneladas de residuos y situados a una distancia menor o igual a $50 \mathrm{~km}$ del gestor autorizado del residuo (Tipo B, Distancia 1): 102,34 $€ / \mathrm{Tm}$.

- Tasa de clausura de vertederos o depósitos incontrolados con una cantidad mayor o igual a 30 toneladas y menor a 150 toneladas de residuos y situados a una distancia mayor de $50 \mathrm{~km}$ del gestor autorizado del residuo (Tipo B, Distancia 2): 107,94 €/Tm.

- Tasa de clausura de vertederos o depósitos incontrolados con una cantidad mayor o igual a 150 toneladas de residuos y situados a una distancia menor o igual a $50 \mathrm{~km}$ del gestor autorizado del residuo (Tipo C, Distancia 1): 59,07 €/Tm.

- Tasa de clausura de vertederos o depósitos incontrolados con una cantidad mayor o igual a 150 toneladas de residuos y situados a una distancia mayor de $50 \mathrm{~km}$ del gestor autorizado del residuo (Tipo C, Distancia 2): 63,27€/Tm.

Y se contemplan, además, tarifas adicionales o especiales para los supuestos en que los residuos extraídos no puedan caracterizarse como residuos de la construcción y demolición, sino del modo siguiente:

— Residuos inertes de baja densidad: $1.657,27 € / \mathrm{Tm}$.

— Residuos de aparatos eléctricos y electrónicos: 466,56 €/Tm.

— Neumáticos: $373,25 € /$ Tm.

— Residuos con aceite mineral: $618,19 € / \mathrm{Tm}$.

— Residuos que contengan amianto: $2.169,50 € / \mathrm{Tm}$.

- Residuos con pintura y disolventes y otros residuos peligrosos no mencionados anteriormente: $2.248,82 € / \mathrm{Tm}$. 


\section{El otorgamiento de concesiones en los montes de utilidad pública}

Finalmente, ${ }_{2}$ debe darse cuenta del nuevo procedimiento de otorgamiento de concesiones administrativas por interés particular en los montes de utilidad pública de la región (de titularidad autonómica o local), aprobado por Orden GAN/16/2012, de 19 de marzo. La disposición se dicta en aplicación de la Ley de Cantabria 3/2006, de 18 de abril, del Patrimonio de la Comunidad Autónoma de Cantabria; de la Ley 43/2003, de 21 de noviembre, de Montes; y del Decreto 485/1962, de 22 de febrero (Reglamento de Montes).

La nueva regulación contempla el otorgamiento de concesiones para (i) el aprovechamiento especial (esto es, sin impedir el uso común, pero con circunstancias de peligrosidad o intensidad, escasez, rentabilidad singular u otras semejantes supongan exceso de utilización sobre el uso que corresponde a todos o un menoscabo de este) por un período mayor de diez años; (ii) el uso privativo del dominio público forestal, ocupándolo de modo que se limite o excluya su utilización por los demás (si este uso se realiza con instalaciones desmontables o bienes muebles por un período no mayor de diez años, estará sujeto a autorización). Las concesiones se otorgarán por un plazo máximo de 75 años, sin perjuicio del derecho de propiedad y a salvo del derecho de terceros.

El procedimiento contempla la emisión de un informe de compatibilidad con la persistencia de los valores naturales del monte (art. 4). Lo emite el Servicio de Montes. Si es desfavorable, la propuesta de resolución será desestimatoria. Si es desfavorable pero con incompatibilidades subsanables, se puede dar o no al interesado la posibilidad de subsanarlas. Y si es favorable, se acompañará de una memoria que contenga la propuesta de pliego de condiciones que ha de regir la concesión. De dicha memoria se dará audiencia al interesado para que alegue lo que le convenga y luego a la entidad titular si no es la solicitante. Si se oponen diferencias insalvables por parte de la entidad propietaria, el Servicio de Montes dictará propuesta de resolución denegatoria de la concesión, elevándola junto con el expediente, para su resolución, al director general competente en materia de montes. Si el interesado renuncia, la entidad titular puede decir si continúa o no el proceso. Si desiste, se deniega la concesión. Si persiste, se continúa el procedimiento a la espera de un nuevo adjudicatario potencial. La falta de resolución expresa en el plazo máximo de tres meses supondrá la desestimación de la pretensión por silencio administrativo negativo. 
La concesión debe adjudicarse con carácter general mediante concurrencia competitiva, aunque excepcionalmente también cabe el otorgamiento directo (supuestos previstos en el artículo 63.4 de la Ley del Patrimonio de Cantabria u otras leyes). 